\title{
Empirical Analysis of Cognitive Dissonance Levels Validation in 3-Dimensional Relationship between Attitude and Behaviour (3D-RAB) Model among Students of King Abdul-Aziz University in Jeddah
}

\author{
Fattheia Hassan Abdulfattah ${ }^{1}$ \\ ${ }^{1}$ Assistant Professor of MIS, Faculty of Economics and Administration, King Abdulaziz University, Jeddah, \\ Kingdom of Saudi Arabia \\ Correspondence: Fattheia Hassan Abdulfattah, Assistant Professor of MIS, Faculty of Economics and \\ Administration, King Abdulaziz University, Jeddah, Kingdom of Saudi Arabia. E-mail: fabdulfatah@kau.edu.sa
}

Received: January 15, 2019

doi:10.5539/ijbm.v14n4p194
Accepted: February 21, 2019 Online Published: March 11, 2019

URL: https://doi.org/10.5539/ijbm.v14n4p194

\begin{abstract}
The study aims to empirically validate the cognitive dissonance levels in the model. A deductive approach has been adopted to measure the validity of cognitive dissonance levels. The main areas of concerns were; current behaviour, attitude towards the target behaviour, attitude towards change or maintain the behaviour, and cognitive dissonance levels. These concepts were examined through a questionnaire analysis. A deductive method has been used to empirically validate the cognitive dissonance levels, which have been proposed in the 3D-RAB model as well as indicate its implication on the persuasive paths. The model suggested that users would experience different level of dissonance for each state. The findings indicated that it is possible that individuals vary in the level and extent in which they experience dissonance. It was also found that there might be other factors that influence the cognitive dissonance levels in relation to the model.
\end{abstract}

Keywords: 3D-RAB model, attitude, behaviour, cognitive dissonance, Jeddah, students

\section{Introduction}

Tecknology represents a powerful influence tool, when humans know how to use it. Many physiological models and theories have been used in technological context, illustrating that the interactions between the human and technology must be taken into account related to physiological aspects; such as, attitude, behaviour, and acceptance (Morris et al., 2012). Persuasive technology is one of the most important domains that focuses on changing the attitude or behaviour through the use of technology. Designers of such technology need to address internal and external personal factors to provide useful persuasive applications (Wiafe, 2012). Many persuasive design models have addressed the designing issues by considering theories of behavioural change. One of these models is the three-dimensional relationship between attitude and behaviour model (3D-RAB), which considers users' attitudes and behaviour in persuasive system design.

Information technology (IT) plays a significant role in personal and social life. Human beings are most likely to interact with cues in their surrounded environment. These responses could influence their attitude and behaviour in many different ways (Oinas-Kukkonen \& Harjumaa, 2008). Thus, technology could be used as a trigger to influence attitudes and behaviours. The term percussive technology is used to describe systems which are designed intentionally to change or influence one's belief or behaviour (Fogg, 2002). Persuasion considered to be the key factor of achieving a change in behaviour or attitude (Oinas-Kukkonen \& Harjumaa, 2008), and its technology deliberates a combination of two disciplines, which are computer-based field and human science (Torning \& Oinas-Kukkonen, 2009).

In persuasive technology world, Wiafi et al. (2011) developed 3D-RAB to analyse the persuasive technology design to identify and categorise different types of users according to the relationship between attitude and behaviour. The main intrapersonal variables in this model are;

- Current Behaviour, which refers to person's existing and current responses or actions within his or her environment 
- Attitude towards target behaviour, which defines as individuals' general evaluation of the target behaviour (Wiafe, 2012).

The model suggests that in addition to attitude towards target behaviour (ATTB), and current behaviour (CB) that are mainly considered in behaviour intervention, a third element which is attitude towards change or maintain behaviour (ATCMB) is also considered. This aspect is associated with change and maintenance of the current behaviour (Wiafe, 2012). According to Wiafi (2012), the third element also affects individual's behavioural intentions and actual behaviour. The previous three intrapersonal respective aggregates provide a positive or negative value towards the target behaviour resulting in creation of 8 different states. The user's types in the 3D-RAB model are based on various levels of cognitive dissonance (CD) states, which categorise them relating to their $\mathrm{CB}$, ATTB, and ATCMB. To date the $3 \mathrm{D}-\mathrm{RAB}$ model is the only model that categorise individuals in states as well as take into account their cognitive dissonance as an approach, while designing persuasive technology (Wiafe, 2012). The development of this model has contributed to the knowledge of persuasive technology field. It considers to be relatively new; therefore, there are some lacks relating to the foundation of the cognitive dissonance levels (CDLs) assessment.

Computers technology play different roles as persuaders and its methods and techniques have been used and developed to change the individuals' attitudes and behaviours (Fogg, 2002). There is an ambiguity demonstrating how persuasion methods and appropriate techniques can be systematically aligned with persuasion technology design (Wiafe, 2012). Moreover, the current persuasive technology applications lack systematic processes during its design phases respecting various natures of users or their use over the time (Wiafe, 2012). In this light, Wiafe et al. (2011) has developed the 3D-RAB model for analysing and implementing behavioural change in persuasive technology as alluded. It represents three dimensional relationships between ATTB, ATCMB, and CB, which distinguishes users into 8 states regarding the targeted behaviour. It helps in selecting the appropriate techniques for persuasive technology design for each type of users (Wiafe, 2012).

The theory of cognitive dissonance mainly means a state of discomfort, which is created when individual holds two or more elements of knowledge that are relevant to each other but inconsistent with one another (Festinger, 1957). According to this theory ones' attitude and behaviour need to be in harmony to avoid this unpleasant state which called "dissonance" (Festinger, 1957). Therefore, the 3D-RAB model suggested that the variation in the states creates no, strong, moderate, and weak cognitive dissonance towards the targeted behaviour. Additionally, the model represents six different paths to the ideal state where one's attitude and behaviour positively matches the targeted behaviour. Therefore, the persuaders can select the appropriate persuasive path to persuade the users according to their current state.

The variation of the cognitive dissonance levels will affect the persuasive paths as suggested by Waife (2012) on basis of the assumption that the levels of cognitive dissonance are correct. The persuaders need to create dissonance before reducing the dissonance to reach the ideal state in the model in some cases where negative behaviour or attitude towards the targeted behaviour is inconsistent. Therefore, the cognitive changeability would affect the design of the persuasive paths to transit from one state to another. The cognitive dissonance levels in the 3D-RAB model have never been empirically tested, as it was based on the assumption which take into account the relationships between CB, ATTB, and ATCMB. Therefore, the 3D-RAB model assumption and the cognitive dissonance theory claim (Festinger, 1957), brings the need to assess whether the previous cognitive dissonance levels assessment (i.e. strong, moderate, weak and none) is correct or not, which has been stated as our key research problem. The present study has assessed the 3D-RAB model summarising its advantages and disadvantages.

\section{Literature Review}

\subsection{Persuasion}

Persuasion is defined as a way of communication that have an intended message to shape, reinforce or change the reactions of an individual towards a target (Miler, 1980). Persuasive communications can concern about cognition, attitude, and behavior (Fogg, 2002), in which persuasion is used to change individuals' beliefs, attitudes, and actions towards a targeted issue or object. Basically, it is an action that influences people to act with conviction in a targeted way. Stiff and Mongeau (2016) claimed that deceptive and coercive could be used as methods of persuasion. However, Simon (1976) illustrated that coercive and deceptive are forms of influence yet they are different than persuasion as they hold negative consequences. Similarly, Kelman (1961) argued that they are not methods of persuasion but they could influence ones' mind effectively.

According to Harjumaa and Kukkonen (2007), persuasion is the key of attitude change. It attempts to change the ways through which individuals think, feel, or act. They have identified three persuasion approaches namely; 
interpersonal, computer-mediated, and human-computer persuasion as shown in figure 1.

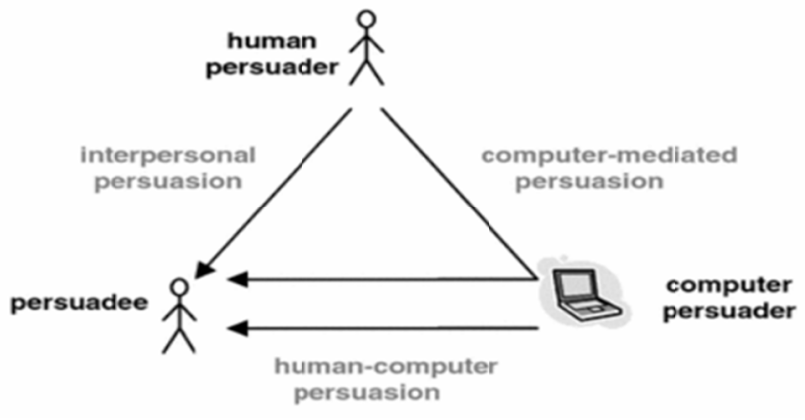

Figure 1. Persuasive Approaches

Source: Harjumaa and Kukkonen, 2007.

Different methods have been used to persuade individuals with the advent of the technology and computers. Computers technologies are playing different roles as persuaders. Persuasive technology (PT) is generally defined as the technology that uses computers technologies to change, form, or reinforce users' attitude or behavior (Harjumaa \& Oinas-Kukkonen, 2007). It sets an example to design with intend that seek a users' behaviour to be acted in a targeted way (Fogg, 2002). In this light, many methods and techniques have been used and developed to affect individuals (e.g. attitude, actions and beliefs). However, there is no consensus or developed methods on how to determine persuasion. Therefore, there is an ambiguity demonstrating how persuasion methods can be systematically aligned with persuasion technology design (Wiafe, 2012). Consequently, the current persuasive technology applications lack systematic processes during its design phases (Wiafe, 2012).

The complexity and misrepresentations in persuasive technology domain lies behind behaviour and attitude change (Wiafe, 2012). This is because, psychologists have not agreed on the nature of attitude and behavior as well as the conclusive links between them (Jowett \& O'Donnell, 2014). Some scholars believed that there is no significant relationship between the attitude and behavior. However, other investigators argued that one's attitude could influences his or her behavior (Ajzen, 1985).

\subsection{Attitude and Behavioural Change Theories}

The major objective for researchers in attitude and behavior change theories was to investigate individual's performance and define factors that influence individual's act in a certain way. For instance, individuals produce a behavior as a result of a relationship between them and their surrounded environment or technology (Morris et al., 2012). According to Davis (1993) user change and influence's methods are seen as the most critical factors in assessing the success or failure of any information system project. Different trends of individual's attitudes and believes have been deliberated to identify users' behavior and actions while developing any information system. Some of the theories such as the Cognitive Dissonance Theory (Festinger, 1957), the Theory of Reasoned Action (Ajzen, 1985), the Theory of Planned Behavior, and other theories have assisted in understanding and analyzing attitude formation and behavior change.

\subsection{Theory of Reason Action (TRA) and Theory of Planned Behavior (TPB)}

According to Sommer (2011), Theory of Planned Behavior has been found to be very useful in predicting a wide range of behaviors such as health-related, recycling, and driving behavior. Additionally, it has been used in behavioral change interventions (Yeo, Rahim \& Ren, 2009). The theory was evolved from the Theory of reason action (Ajzen, 1985), which suggested that individuals' behavior is determined by his/her intention to not or perform such a behavior. Based on this theory, one's intention is influenced by two factors;

- Attitude toward the behavior, which refer to the general feeling of favorableness or unfavourableness of the behavior (Ajzen \& Fishbein, 1980).

- Subjective Norm, which is defined as the persons' perception of the impacted views of important people in his/her life if he/she should perform such a behavior or not (Ajzen \& Fishbein, 1980).

Moreover, Ajzen (1991) claimed that attitude could predict the behavior by adding 'perceived behavioral control' to the theory of reasoned action as it refers to the factors that may simplify or inhibit the performance of the behavior (Jowett \& O'donnell, 2014). The theory acknowledged that beliefs, attitudes, norms, and intentions are 
the main factors that determine the ultimate behavior. Ajzen (1991) argued that intentions are the motivations that influence behavior as well as specify the effort that is employed to perform that behavior (Figure 2).

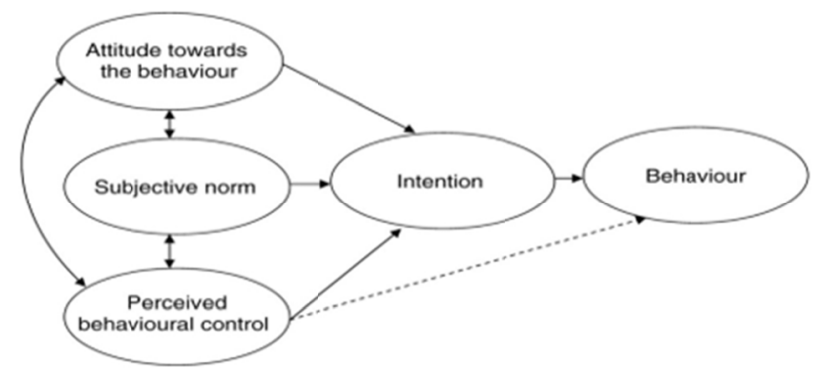

Figure 错误!文档中没有指定样式的文字。. The Theory of Planned Behavior

Source: Ajzen, 1991.

\subsection{Theory of Cognitive Dissonance}

The theory of cognitive dissonance was suggested by Festinger (1957) that immediately has raised interest in psychology (Cummings \& Venkatesan, 1976). It is suggested that individuals have an internal motive to embrace their attitudes and beliefs in harmony and avoid disharmony or dissonance (Festinger, 1957). In principle, dissonance represents an unpleasant psychological state that arises from discrepancy between the knowledge one may hold and the actual behaviour (Festinger, 1957). This uncomfortable feeling will lead to alter or adjust one of the attitudes, beliefs or behaviours to eliminate the tension of dissonance and maintain balance (Festinger, 1957). Therefore, individuals attempt to coincide their attitude with their actions when contradiction occurs between them (Figure 3).

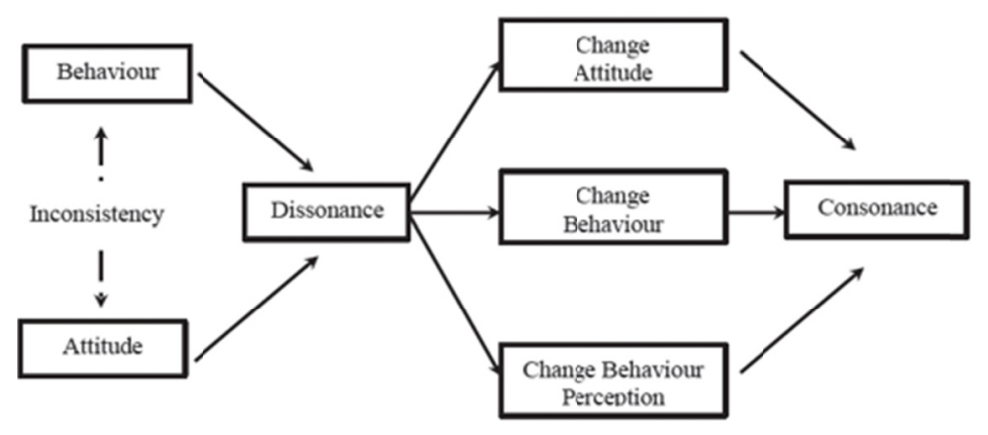

Figure 3. Theory of cognitive dissonance

Source: Festinger, 1957.

The cognitive dissonance theory gained great popularity in academic world and have been further studied and observed in social psychology (Harmon-Jones \& Harmon-Jones, 2007). The theoretical urge to understand some or all the relationships in cognitive dissonance theory have derived researches to conduct various experiments to revisit the theory (Cooper \& Fazio, 1984). Moreover, the theoretical studies of cognitive dissonance have assisted in the delivery of self-theories such as the self-affirmation theory and self-consistency theory (Aronson, 1969), and other work on dissonance such as the role of self-attribute accessibility in dissonance (Stone \& Cooper, 2001).

According to Festinger (1957), cognitions mean any knowledge, opinion, or belief about oneself or ones' behaviour or about the environment. Thus, there are different experiments, which have been used to find out if dissonance is likely to occur when ones' experience shows inconsistency, when relations among cognitions are non-harmonious. Attempts to establish dissonance have included direct and indirect experiments. They have been reported in several issues of marketing and psychology journals. Anxiety, comfort, and feelings have been 
used as psychological measures, as for behavioural measures were designed to establish dissonance reduction (Sweeney, Hausknecht \& Soutar, 2000). Many empirical examinations of dissonance theory have employed dissonance experimentally within paradigms. For example, the disconfirmation paradigm was used to examine dissonance reduction (Sweeney, Hausknecht \& Soutar, 2000).

Dissonance has been also measured by examining the opinions of the subject at different stages of an experiment (Sweeney, Hausknecht \& Soutar, 2000). A study by Cooper and Fazio (1984) suggested that dissonance arousal is necessary to the occurrence of the dissonance uncomfortable state. However, dissonance as psychological uncomfortable state has not been given empirical attention as much as dissonance arousal experiments (Elliot \& Devine, 1994). Supportively, Soutar and Sweeney (2003), have discussed the need to examine dissonance as uncomfortable state and moreover to observe dissonance differently taking into account variation in dissonance. Waife et.al. (2011) developed a model that categorises individuals in states regarding their attitudes and behaviour linking them to different levels of cognitive dissonance.

\subsection{Three-Dimensional Relationship between Attitude and Behaviour Model (3D-RAB)}

The 3D-RAB model signifies three-dimensional relationship between attitude towards behaviour, attitude towards change or maintaining a change, and current behaviour. Thus, by examining these three factors persuaders can analyse users' states during persuasive interventions. Each attribute in the model is presented by parametric variation of values positive or negative for each of the dimensions, which helps in differentiate peoples' states into 8 categories (Wiafe, 2012).

According to Wiafe (2012), attitude towards targeted behaviour can be positive behaviour when a person favours the targeted behaviour. However, the attitude towards behaviour is not always in harmony with the current behaviour. Similarly, the attitude towards changing or maintaining the current behaviour can be positive when a person agrees to change the current behaviour to the targeted one or agree to maintain the current behaviour if it matches the targeted behaviour and negative otherwise (Wiafe, 2012). This factor assists in knowing the persons' willingness and readiness of changing or maintains the current behaviour. However, self-efficiency plays a key role in influencing ATCMB as people who feel less confident or unable to accomplish a task are likely to have negative attitude to change their existing behaviour (Wiafe, 2012). While for the third factor the current behaviour Wiafe (2012) has identified it as the existing action within the environment which will be positive if it matches the target behaviour and will considered negative otherwise. However, there is a need to have a target or reference behaviour to personalise the measurement to measure the behaviour (Wiafe, 2012).

\section{Research Methodology}

\subsection{Research Approach}

The two main research approaches were widely used for conducting studies include; deductive and inductive approaches. In terms of the deductive approach, Saunders, Lewis \& Thornhill (2009) claimed that it primary involved concern about testing and developing a theory that is subjected to a test. Conversely, the inductive approach focuses on exploring data and develop theories from them (Saunders, Lewis \& Thornhill, 2009). Researches in this context have a clear and defined purpose as well as do not start with any fixed theories or theoretical frameworks (Saunders, Lewis \& Thornhill, 2009). Scholars in this context are focusing on observing why events are likely to occur on small sample subjects, unlike the deductive research which require a larger sample (Saunders, Lewis \& Thornhill, 2009). The present study has aimed to empirically validate the cognitive dissonance levels, which have been proposed in the 3D-RAB model as well as indicate its implication on the persuasive paths. Therefore, deductive approach is used to examine an assumption and design a research strategy to test this theory (Saunders, Lewis \& Thornhill, 2009).

The purpose of the $3 \mathrm{D}-\mathrm{RAB}$ model is to categorize individuals according to their state. The model suggested that users would experience different level of dissonance for each state. Thus, it is possible to draw some hypotheses reflecting the theoretical assumption in the $3 \mathrm{D}-\mathrm{RAB}$ as;

- $\quad \mathrm{H} 1$ : State $1(\mathrm{~S} 1)(\mathrm{CB}+),(\mathrm{ATTB}+),(\mathrm{ATCMB}+)=$ no dissonance.

- $\quad \mathrm{H} 2$ : State $2(\mathrm{~S} 2)(\mathrm{CB}+),(\mathrm{ATTB}+),(\mathrm{ATCMB}-)=$ weak dissonance.

- $\quad \mathrm{H} 3$ : State $3(\mathrm{~S} 3)(\mathrm{CB}+),(\mathrm{ATTB}-),(\mathrm{ATCMB}+)=$ moderate dissonance.

- $\quad$ H4: State $4(\mathrm{~S} 4)(\mathrm{CB}+),(\mathrm{ATTB}-),(\mathrm{ATCMB}-)=$ strong dissonance.

- $\quad \mathrm{H} 5$ : State $5(\mathrm{~S} 5)(\mathrm{CB}-),(\mathrm{ATTB}+),(\mathrm{ATCMB}+)=$ strong dissonance.

- $\quad \mathrm{H} 6$ : State $6(\mathrm{S6})(\mathrm{CB}-),(\mathrm{ATTB}+),(\mathrm{ATCMB}-)=$ moderate dissonance. 
- $\quad$ H7: State 7 (S7) (CB -), (ATTB -), (ATCMB +) = weak dissonance.

- $\quad$ H8: State 8 (S8) (CB -), (ATTB -), (ATCMB -) = no dissonance.

The adoption of a deductive approach seems to fit the research aim and objectives and allows to test the hypotheses and the validity of an existing model and subsequently draw a conclusion. It can be done by adopting Robenson (2002) five sequential stages for deductive approach (Figure 4). Moreover, the study has followed quantitative method because the results and data will be scientifically measured to discover the correctness of the cognitive dissonance levels in the model.

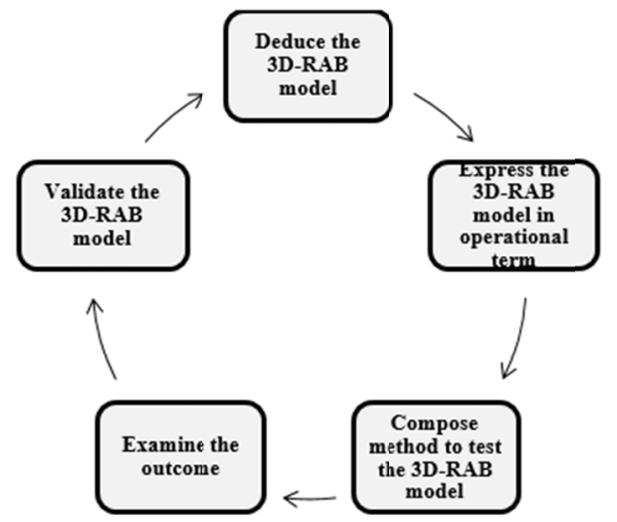

Figure 4. Research stages (Deductive approach)

\subsection{Research Strategy}

The study has adopted a survey strategy, since the main aim is to evaluate our proposed theoretical hypotheses.

\subsection{Research Instrument}

The survey method; specifically, questionnaire, has been used to empirically validate the model. A questionnaire has been designed to assess the point of each state categorically and formulate questions to measure the 3 factors adopted from the $3 \mathrm{D}-\mathrm{RAB}$ as well as the level of dissonance in each state.

\subsection{Questionnaire Design}

A questionnaire was designed to collect relevant data from individuals. Specifically, the goal was to identify their behaviour and attitude towards 8 different topics in relation to green and healthy living. According to the 3D-RAB model the target behaviour need to be specific to measure individuals' current behaviour, attitude towards the target behaviour, and attitude towards changing or maintaining the current behaviour.

\subsection{Data Collection and Sampling}

The questionnaire was designed in two languages that are Arabic and English to reach larger random individuals from different countries and it was distributed through online tool (Survey Monkey) vila internet using emails and social media. The distribution of the questionnaire started in June 2017 and 148 respondents took part in the questionnaire during nearly three weeks. Out of the total responses; 26 were excluded due to incompletion or inappropriate responses; however, 122 were used for the analysis. The total sample was 976 (122 participant*8 topics), since the study had 8 different topics in the questionnaire and each of which represents different states and level of cognitive dissonance for each individual.

\subsection{Data Analysis}

The respondents were classified into having a positive or negative behaviour by answering yes or no questions regarding the $\mathrm{CB}$ and $\mathrm{ATCMB}$, since the questionnaire was designed according to the 3D-RAB model concepts (CB, ATTB, ATCMB and CDLs). As for respondents ATTB, four-point Likert scale was used and the mean of the numerical values of the responses were calculated representing their positive or negative ATTB. In this research, it was defined that ATTB mean values less than 3 were considered to be negative and positive otherwise. Similarly, the cognitive dissonance levels were assessed using the mean of the response's numerical values.

\section{Results}

The 3D-RAB model attributes were used to identify respondents' states as well as CDLs for each respondent in 
each state. The analysis of the level of cognitive dissonance for each respondent in a particular state for each topic was mapped to the actual model. The evaluation has helped to assist the testing of research hypotheses leading to draw our conclusion in relation to CDLs validity. It was observed that the majority of the respondents are in state 1 which matches the higher number of positive frequency and percentage appeared in the analysis of $\mathrm{CB}$, ATTB, and ATCMB by exploring respondents CB, ATTB, and ATCMB. According to the 3D-RAB model, individuals experience no dissonance if their $\mathrm{CB}$, ATTB, and ATCMB are alike. All the respondents who are in state 1 or state 8 experienced no dissonance. This was also applicable for the observation of the higher means.

$$
\text { S2-S7 = Weak Dissonance }
$$

Respondents, who were in S2, have a positive CB and ATTB which disagree with their ATCMB. From the observations, there was only one respondent in this state, who experienced a weak level of dissonance. However, when using higher mean value, the respondent seems to experience moderate dissonance (Table 1). Therefore, $\mathrm{H} 2$ was rejected by the second definition and appeared to be reliable in the first one. However, this variation is less likely to be acceptable as it was only for one participant. As for S7, the percentage of the matching between ACDL and PCDL in S7 were $83.3 \%$ for both CDLs means definitions. Additionally, $\mathrm{H} 7$ test indicated that S7 participants experience weak level of dissonance, which supports the hypothesis for this state.

\section{S3-S6 = Moderate Dissonance}

The hypotheses suggested that individuals, who are in S3 and S6 would experience moderate level of cognitive dissonance. Reflections of respondents' results showed a matching between ACDL and PCDL. Additionally, the hypothesis test indicated that participants experienced a moderate cognitive dissonance level towards disposing their ICT appropriately for both high and low means results. Therefore, it can be said that the hypothesis for S3 and $\mathrm{S} 6$ proved its accuracy in relation to this topic.

\section{S5 = Strong Dissonance}

Only 2 in S5 out of 47 respondents experienced strong level of dissonance towards disposing ICT waste appropriately, when the mean was rounded to the lower value. Reassuringly, $95.7 \%$ was the percentage of the mismatch between ACDL and PCDL, which indicated that the level of dissonance of majority of the respondents in S5 is not matching the PCDL. Additionally, the results showed that participants in S5 experienced different levels of $\mathrm{CD}$, which were varied between none and strong (Table 1). As a result, the hypothesis for this state was rejected for both means definition. It is due to the high percentage of mismatch between ACDL and PCDL, as well as the hypothesis test for this state supported this rejection.

Table 1. Comparison between ACDL1 and PCDL1

\begin{tabular}{|c|c|c|c|c|c|c|c|c|c|c|}
\hline \multirow{3}{*}{$\begin{array}{l}\text { State } \\
\text { S1 }\end{array}$} & \multicolumn{4}{|c|}{ ACDL1 mean to the Lower } & \multirow{3}{*}{$\begin{array}{l}\text { Total } \\
51\end{array}$} & \multicolumn{5}{|c|}{ ACDL1 } \\
\hline & None & Weak & Moderate & Strong & & \multicolumn{2}{|c|}{ Match PCDL } & \multicolumn{2}{|c|}{ Mismatch PCDL } & \multirow{2}{*}{$\frac{\text { Total }}{100 \%}$} \\
\hline & 51 & 0 & 0 & 0 & & 51 & $100 \%$ & 0 & $0 \%$ & \\
\hline S2 & 0 & 1 & 0 & 0 & 1 & 1 & $100 \%$ & 0 & $0 \%$ & $100 \%$ \\
\hline S3 & 0 & 2 & 1 & 0 & 3 & 1 & $33.3 \%$ & 2 & $66.7 \%$ & $100 \%$ \\
\hline S5 & 6 & 19 & 20 & 2 & 47 & 2 & $4.3 \%$ & 45 & $95.7 \%$ & $100 \%$ \\
\hline S6 & 0 & 3 & 8 & 0 & 11 & 8 & $72.7 \%$ & 3 & $27.3 \%$ & $100 \%$ \\
\hline S7 & 0 & 5 & 1 & 0 & 6 & 5 & $83.3 \%$ & 1 & $16.7 \%$ & $100 \%$ \\
\hline S8 & 3 & 0 & 0 & 0 & 3 & 3 & $100 \%$ & 0 & $0 \%$ & $100 \%$ \\
\hline Total & 60 & 31 & 29 & 2 & 122 & 70 & $57.4 \%$ & 52 & $42.6 \%$ & $100 \%$ \\
\hline State & \multicolumn{4}{|c|}{ ACDL1 mean to the Higher } & Total & \multicolumn{4}{|c|}{ ACDL1 } & Total \\
\hline S1 & 47 & 4 & 0 & 0 & 51 & 47 & $92.2 \%$ & 4 & $7.8 \%$ & $100 \%$ \\
\hline $\mathrm{S} 2$ & 0 & 0 & 1 & 0 & 1 & 0 & $0 \%$ & 1 & $100 \%$ & $100 \%$ \\
\hline S3 & 0 & 1 & 2 & 0 & 3 & 2 & $66.7 \%$ & 1 & $33.3 \%$ & $100 \%$ \\
\hline S5 & 2 & 17 & 21 & 7 & 47 & 7 & $14.9 \%$ & 40 & $85.1 \%$ & $100 \%$ \\
\hline S6 & 0 & 2 & 7 & 2 & 11 & 7 & $63.6 \%$ & 4 & $36.4 \%$ & $100 \%$ \\
\hline S7 & 0 & 5 & 1 & 0 & 6 & 5 & $83.3 \%$ & 1 & $16.7 \%$ & $100 \%$ \\
\hline S8 & 3 & 0 & 0 & 0 & 3 & 3 & $100 \%$ & 0 & $0 \%$ & $100 \%$ \\
\hline Total & 52 & 29 & 32 & 9 & 122 & 71 & $58.2 \%$ & 51 & $41.8 \%$ & $100 \%$ \\
\hline
\end{tabular}

Overall, H1, H3, H6, H7, and H8 were accepted in terms of appropriate disposal of ICT waste. On the other hand, H5 were disconfirmed by both CDL means definition, which means that respondents in S5 have not experience strong CDLs in terms this issue. As for, $\mathrm{H} 2$ was approved in the first mean definition and rejected otherwise. However, this difference between the $\mathrm{H} 2$ reliability could be affected by the number of participants in this state as only one participant was representing it. 
Table 2. Comparison between the hypotheses reliability regarding low and high CDL mean value

\begin{tabular}{|c|c|c|c|c|c|c|c|c|}
\hline CDL & H1 & $\mathrm{H} 2$ & $\mathrm{H} 3$ & $\mathrm{H} 4$ & H5 & H6 & $\mathrm{H} 7$ & H8 \\
\hline Mean to the lower & Accept & Accept & Accept & & Reject & Accept & Accept & Accept \\
\hline Mean to the higher & Accept & $\begin{array}{l}\text { Reject } \\
1\end{array}$ & Accept & & Reject & Accept & Accept & Accept \\
\hline Match \% & $85.7 \%$ & & & & Mismat & $h \%$ & $14.3 \%$ & \\
\hline
\end{tabular}

\section{Discussion}

From the above evaluation, it can be inferred that the CDLs in terms of the 3D-RAB model attributes has taken tow-sided. It was observed that when individuals CB and ATTB are equal (S1, S2, S7 and S8) no matter if it matches the ATCMB or not the levels of dissonance are appeared to be accurate. In S1 and S8; individuals have no cognitive dissonance due to the agreement between their cognition which results in no psychological tension (Wiafe, 2012). While, individuals in S2 and S7 experienced weak CDL. It is due to the agreement between CB and ATTB, in which it creates a strong consonance; however, the dissonance was created due to the negative value for ATCMB (Wiafe, 2012), which explains why participants experience a weak level of dissonance in such states.

On the other hand, when individuals CB and ATTB are unequal (S3, S5, and S6) no matter if they agree with the ATCMB or not the levels of dissonance appear to be questionable. This was apart from $\mathrm{S} 4$ as it has been accepted due to the match between ACDL and PCDL. Yet, the results for this state might be the same as the previous states as only one participant was representing this state and the hypothesis was testing accordingly. However, when examining the hypotheses of S3, S5, S6 per state, topic or overall, they appear to be consonantly rejected. Thus, it can be indicated that strong and moderate levels of dissonance in terms of the model attributes have not proofed their reliability. This is because the disagreement between the PCDL and ACDL for those states was significant. Additionally, the CDLs in S3, S5 and S6 generally appear to shift towards the lower levels of dissonance. Therefore, in general, from the above observation and discussion it can be said that;

- $\quad \mathrm{H} 1: \mathrm{S} 1(\mathrm{CB}+),(\mathrm{ATTB}+),(\mathrm{ATCMB}+)=$ no dissonance.

- $\quad \mathrm{H} 2: \mathrm{S} 2(\mathrm{CB}+),(\mathrm{ATTB}+),(\mathrm{ATCMB}-)=$ weak dissonance.

- $\quad \mathrm{H} 3: \mathrm{S} 3(\mathrm{CB}+),(\mathrm{ATTB}-),(\mathrm{ATCMB}+) \neq$ moderate dissonance.

- $\quad \mathrm{H} 4: \mathrm{S} 4(\mathrm{CB}+),(\mathrm{ATTB}-),(\mathrm{ATCMB}-)=$ strong dissonance.

- $\quad \mathrm{H} 5$ : S5 (CB -), (ATTB +$),(\mathrm{ATCMB}+) \neq$ strong dissonance.

- $\quad \mathrm{H} 6: \mathrm{S6}(\mathrm{CB}-),(\mathrm{ATTB}+),(\mathrm{ATCMB}-) \neq$ moderate dissonance.

- $\quad$ H7: S7 (CB -), (ATTB -), (ATCMB +) = weak dissonance.

- $\quad$ H8: S8 (CB -), (ATTB -), (ATCMB -) = no dissonance.

Cooper (2007) has stated that the increased stressed and tense results in reduction of the dissonance. Therefore, the urge to reduce the uncomfortable state might decrease the level of dissonance. It could be done by reducing the importance of the conflicting cognitions and acquire another belief (Festinger, 1957). For example, individuals in S3 and S6 could take into account the agreement between their CB and ATCMB and ignore the discrepancy between ATTB and CB to reduce the dissonance from moderate to weak or none. Similarly, the agreement between the ATTB and ATCBM in S5 could play a role in eliminating the level of dissonance. In psychology; confirmation evidence or bias refers to ones' tendency to look for interpretation which confirms his/her beliefs or hypothesis.

It can be said that an alternative way to eliminate the dissonance is by seeking the confirming evidence and disregarding the impact of the disconfirming evidence. For instance, in S5 the disconfirming evidence could be the noticeable discrepancy between ones negative CB, and positive ATTB and ATCMB. However, the agreement between ATTB and ATCBM could be seen as confirming evidence. In other words, adding a consonant cognition by recalling the positive anticipation to change the negative behaviour to a positive one in the future (i.e. ATCMB) to minimise the dissonance. It can be suggested that individuals in S5 could evoke the tendency to change their unhealthy eating habits (ATCMB) as confirming evidence to reduce the confliction between their positive attitudes and negative behaviour.

In the same light, another way to reduce the dissonance could be by rationalising the behaviour respecting the attitude or vice versa. It means to seek confirming information for the mismatching cognitions to minimise the impact of the dissonance (Festinger, 1957). For example, it can be argued that although people have a negative 
$\mathrm{CB}$ and positive attitude $(\mathrm{S} 5+\mathrm{S} 6)$ towards doing regular exercise, they still could reduce the high or moderate dissonance level by seeking confirming information. For instance, considering common problems of doing regular exercise such as chronic pain or alternatively looking for excuses to justify their negative behaviour towards exercise.

Dissonance can be reduced, when one interprets the significance of different cognitions (Cooper, 2007). Therefore, it can be suggested that the inconsequence of the issue could be the reason for the CDLs reduction from higher to lower levels. This variation could reflect the importance of the topic for each person. For example, strong level of dissonance was experienced by minority of the sample, when it comes to green initiatives topics; such as ICT disposal, printing, and ICT energy consumption. It has been observed that the matching between ACDL and PCDL might be influenced by the importance of the topic. Cooper (2007) argued that dissonance has a magnitude which will be based on the disagreement between two cognitions. The study stated that the more disagreement between cognition is the more discomfort state is likely to occur. Thus, in this light it could be argued that the more important the issue is, the more likely higher dissonance levels could be observed. For instance, the significance of doing regular exercise issue and its impact on health could be the reason that S5 witness an increase in strong $\mathrm{CD}$ among its members compared to other issues.

The interpretations of states distribution could support that CDLs are related to the importance of the issue been discussed. For example, no one have been categorised in negative unstable states such as S7 and S8 when water conservation and unhealthy food topics were discussed. This could demonstrate that those issues are widely seen important as no participant held a negative ATTB towards them. Supportively, observations show that the same participant has been categorised in different states and has different levels of dissonance in relation to the topic. For instance, one of the respondents was in $\mathrm{S} 1$ and had no dissonance regarding food wastage topic while she was in S5 and experience moderate level of dissonance in terms of regular exercise issue. This indicates that CDLs are subjective as well as could be experienced differently respecting the issues were discussed.

The 3D-RAB model attributes were order to identify respondents' ACDLs this was done linking participants CB, ATTB and ATCMB to the CDLs. The ACDL was compared to the PCDL using the agreement percentage between them as an indicator to test the accuracy of each hypothesis, besides the usage of the T-statistic hypothesis test. Additionally, the test and comparison were made in both CDL mean definition to assure the reliability of the evaluation. Moreover, the observations of comparing ACDL to PCDL were used as a determinate to assess the validity of each hypothesis. By doing so, the study identified that lower CDLs (i.e. none and weak) appear to be accurate and higher levels (i.e. moderate and strong) seem to be questionable. Additionally, possible factors that influenced CDLs were discussed as well it was suggested that the importance of the topic has an impact on the accuracy of the CDLs. Furthermore, this was linked to the CDLs implication on the possible transition pathways which have been proposed by the model.

\section{Conclusion}

The results have suggested that there is a need to examine the uncomfortable state and observe dissonance differently in terms of variation on its levels. Thus, the purpose of this research was to empirically validate the CDLs in the 3D-RAB model by conducting a deductive approach. The research initiated by a literature review and deduced the 3D-RAB model, followed by the influence of the CDLs on the persuasive paths. Consequently, a questionnaire has been conducted to estimate the validity of the CDLs in the model. The results showed improvement in the accuracy of no and weak dissonance levels. However, the accuracy of moderate and strong dissonance levels has been disapproved. The dissonance reduction methods might play a role in rejecting high CDLs. Moreover, the validation of the CDLs has an impact of the proposed persuasive pathways. The conclusions drawn from this study can be employed to enrich the understanding of the potential of CDLs. It has also highlighted the CDLs implication on the persuasive pathways. Thus, persuasive technology designer could benefit from the provided results, while adopting the 3D-RAB model categorisation as an approach of persuasion. It could be done by designing persuasive systems, which fit each state in relation to the validity of the CDLs. The consequence of discussed issues is subjective to the person as well as they differ in perception from one to another. Thus, the introduction of this factor (importance of the issue) could generally be seen as a new attribute to CDLs validity. Further studies need to examine the transition pathways in the model, as CDLs implication considered to be against the nature of human beings that tend to reduce cognition conflictions.

\section{Acknowledgement}

The author is very thankful to all the associated personnel in any reference that contributed in/for the purpose of this research. Further, this research holds no conflict of interest and is not funded through any source. 


\section{References}

Ajzen, I. (1985). From intentions to actions: A theory of planned behavior. Action Control (pp. 11-39). Springer Berlin Heidelberg.

Ajzen, I. (1991). The theory of planned behavior. Organizational Behavior and Human Decision Processes, 50(2), 179-211.

Ajzen, I., \& Martin, F. (1980). Understanding attitudes and predicting social behaviour.

Aronson, E. (1969). The Theory of Cognitive Dissonance: A Current Perspective. In Advances in experimental social psychology (Vol. 4, pp. 1-34). Academic Press.

Cooper, J. (2007). Cognitive dissonance: 50 years of a classic theory.

Cooper, J., \& Russell, H. F. (1984). A new look at dissonance theory. In Advances in experimental social psychology (Vol. 17, pp. 229-266). Academic Press.

Cummings, W. H., \& Venkatesan, M. (1976). Cognitive dissonance and consumer behavior: A review of the evidence. Journal of Marketing Research, 303-08.

Davis, F. D. (1993). User acceptance of information technology: system characteristics, user perceptions and behavioral impacts. International Journal of Man-Machine Studies, 38(3), 475-87.

Elliot, A. J., \& Patricia, G. D. (1994). On the motivational nature of cognitive dissonance: Dissonance as psychological discomfort. Journal of Personality and Social Psychology, 67(3), 382.

Festinger, L. (1957). A theory of cognitive dissonance (Vol. 2). Stanford university press.

Fogg, B. J. (2002). Persuasive technology: using computers to change what we think and do. Ubiquity, 5.

Harjumaa, M., \& Harri, O. K. (2007). Persuasion theories and IT design. In International Conference on Persuasive Technology (pp. 311-314). Springer, Berlin, Heidelberg.

Harmon-Jones, E., \& Cindy, H. J. (2007) . Cognitive dissonance theory after 50 years of development. Zeitschrift für Sozialpsychologie, 38(1), 7-16.

Jowett, G. S., \& O’donnell, V. (2014). Propaganda \& persuasion.

Kelman, H. C. (1961). Processes of opinion change. Public Opinion Quarterly, 18(9), 25-57.

Lockton, D., David, H., \& Neville, S. (2008). Design with intent: Persuasive technology in a wider context. In International Conference on Persuasive Technology (pp. 274-278). Springer, Berlin, Heidelberg.

Millar, G. (1980). Persuasion: New directions in Theory and research.

Morris, J. M., Marzano, N. D., \& O’brien, L. (2012). Theories and models of behaviour and behaviour change. Forest Research. United Kingdom: Surrey.

Oinas-Kukkonen, H., \& Marja, H. (2008). A systematic framework for designing and evaluating persuasive systems. In International conference on persuasive technology (pp. 164-176). Springer, Berlin, Heidelberg.

Robson, C. (2002). Real World Research: A Resource for Social Scientists and Practitioner-Researchers (2nd ed.). Blackwell Publishing: Oxford, UK.

Saunders, M., Philip, L., \& Adrian, T. (2009). For Business Students (5th ed).

Simon, H. A. (1976). Administrative Behaviour. New York.

Sommer, L. (2011). The theory of planned behaviour and the impact of past behaviour. The International Business \& Economics Research Journal, 10(1), 91.

Soutar, G. N., \& Jillian, C. S. (2003). Are there cognitive dissonance segments? Australian Journal of Management, 28(3), 227-249.

Stiff, J. B., \& Paul, A. M. (2016). Persuasive communication. Guilford Publications.

Stone, J., \& Joel, C. (2001). A self-standards model of cognitive dissonance. Journal of Experimental Social Psychology, 37(3), 228-243.

Sweeney, J. C., Douglas, H., \& Geoffrey, N. S. (2000). Cognitive dissonance after purchase: A multidimensional scale. Psychology and Marketing, 17(5), 369-385.

Torning, K., \& Harri, O. K. (2009). Persuasive system design: state of the art and future directions. In Proceedings of the 4th international conference on persuasive technology (p. 30). ACM. 
Wiafe, I. (2012). A Framework for Analysing, Designing and Evaluating Persuasive Technologies (Doctoral dissertation, $\mathrm{PhD}$ Thesis submitted to the University of Reading.

Wiafe, I., Keiichi, N., Stuart, M., \& Stephen, R. G. (2011). Considering user attitude and behaviour in persuasive systems design: The 3d-rab model. In ECIS (p. 186).

Yeo, A. C., Mahbubur, R., \& Yin, Y. R. (2009). Use of Persuasive technology to change end user's IT security aware behavior: a pilot study. International Journal of Human and Social Sciences, 4(9), 673-679.

\section{Copyrights}

Copyright for this article is retained by the author(s), with first publication rights granted to the journal.

This is an open-access article distributed under the terms and conditions of the Creative Commons Attribution license (http://creativecommons.org/licenses/by/4.0/). 